\title{
Measures of Spatial and Demographic Disparities in Access to Urban Green Space in Harbin, China
}

\author{
Qian Xie (iD) and Ming Lu (1) \\ School of Architecture, Harbin Institute of Technology, \\ Key Laboratory of Cold Region Urban and Rural Human Settlement Environment Science and Technology, \\ Ministry of Industry and Information Technology, Harbin 150006, China \\ Correspondence should be addressed to Ming Lu; hitlm@126.com
}

Received 24 August 2020; Revised 5 November 2020; Accepted 11 November 2020; Published 1 December 2020

Academic Editor: Jun Yang

Copyright (c) 2020 Qian Xie and Ming Lu. This is an open access article distributed under the Creative Commons Attribution License, which permits unrestricted use, distribution, and reproduction in any medium, provided the original work is properly cited.

\begin{abstract}
Access to urban green space (UGS) is associated with the enhancement of health and disparities in access generate issues of spatial equity and socioenvironmental justice. The aim of this study is to measure spatial accessibility and investigate access disparities to UGSs in urban areas of Harbin, China. A Gaussian-based two-step floating catchment area method and spatial autocorrelation analysis were used to measure the accessibility and evaluate its distribution patterns in residential tracts. Bivariate correlation was employed to examine the statistical relations between demographic characteristics of residential tracts and green space access. The results show that most residential tracts have minimal green space access within walking distance, while a few have limited access within cycling distance. Additionally, spatial disparities were found with low-accessibility tracts clustering in the center of the city, while high-accessibility tracts were located in northern and southern suburbs. Demographic disparities were also identified in the study: females have less access to UGS than males, areas with a high birth rate generally have more access, and population density is negatively associated with UGS access. The findings not only indicate that Harbin has an uneven distribution and disproportionate provision of UGS for urban residents but also identify which areas and population groups within the city are disadvantaged in access to UGS and thus provide suggestions for future construction and provision of UGS.
\end{abstract}

\section{Introduction}

Urban green spaces (UGSs) are the primary places within cities that offer inhabitants opportunities to engage in recreational and physical activities [1]. Research has found that access to UGS can effectively contribute to enhancing health and well-being, especially in terms of physical activity improvement, stress relief, weight loss, mortality reduction, and prevention of chronic diseases [2-7]. Since UGS is a public environmental and natural resource that can supply urban ecosystem services and bring great health benefits to urban inhabitants $[8,9]$, access to UGS has become a popular research topic. Many studies consider green space accessibility a spatial or socioenvironmental justice issue [10-15]. Currently, achieving spatial and social-environmental equity has become the goal of UGS provision, which holds that people should have equitable opportunities to access and benefit from UGS independent of the location of their residence, demographic characteristics, or socioeconomic status [16-19]. However, disparities in access and uneven distribution of UGS in urban areas occur all over the world. Therefore, measuring disparity and inequity becomes a necessary task in an attempt to achieve more equitable UGS provisions within a city. Generally, the task consists of three main processes: (i) measuring accessibility to UGS, (ii) evaluating disparities, and (iii) identifying which groups that have less access to UGS.

Measuring accessibility to UGS is the fundamental step in identifying the disparities. Even though Wolch (2014) 
stated that previous studies have not reached a consensus about how to measure accessibility to UGS [2], there are two primary parameters: proximity and quantity of UGS. First, UGS proximity is one of the determining factors of green space access, which is associated with the level of physical activities [20]. More UGS within a walking space positively correlates with park use [7]. A widely used approach for measuring access from the perspective of proximity is to generate a UGS service area (catchment), which is defined as an area influenced by an individual UGS [21]. The service area determines the users who can potentially access the green space based on Euclidean distance and network distance, and the interval of distance depends on the mobility of users. Given that the range of walking speed is $2-10 \mathrm{~km} / \mathrm{h}$ and the average speed is $4.8 \mathrm{~km} / \mathrm{h}$ [22], scholars have used a variety of threshold times and distances to define the service area (catchment) of a UGS. Boyle (1983) described how park users tend to visit a park within $500 \mathrm{~m}$ of their residence [23], which is approximately a seven-minute walking distance; the European Environment Agency advocates that UGSs be placed within $15 \mathrm{~min}$ walking distance from visitors (900-1,000 m) [24]. Similarly, some scholars indicate that $1,000 \mathrm{~m}$ is the critical distance between residents and parks because the average leisure walking distance in North America is 2,000 $\mathrm{m}[25,26]$. Wright Wendel claimed that the size of green space catchment should be associated with its acreage; for large green spaces such as urban parks, the service area (catchment) can be delineated as a $1,600 \mathrm{~m}$ buffer [27]. Additionally, Pham and Labbé noted that the critical distance for park visitation can be extended to 2,500 $\mathrm{m}$ when considering cycling modes [28].

The second parameter to measure accessibility is UGS quantity, which describes the amount or acreage of UGS to which an individual has access. A low quantity of UGS might result in "green space pressure," which indicates potential need and congestion [13]. The method for measuring UGS quantity is mainly based on either "population-ratio" or "area-percentage." However, the two-step floating catchment area (2SFCA) method, an approach that integrates both proximity and quantity parameters to measure access, was proposed by Radke and $\mathrm{Mu}$ (2000) [29] and named by Luo and Wang (2003) [30]. The method includes operations that generate both a UGS service area (catchment) and calculate population-ratio. In recent years, many further improvements to this approach have emerged, including enhanced 2SFCA [31], kernel 2SFCA [32], variable 2SFCA [33], and Gaussian S2FCA [34]; the primary differences between them are the considerations of "distance effect" in the function. These methods have been applied to the measures of accessibility to health care and food stores [30-32, 34, 35]. However, studies on UGS accessibility and disparity are still limited, particularly in developing countries.

There are two frequently used measures of disparity in accessibility: spatial disparity and population disparity (i.e., demographic and socioeconomic disparity). Research on spatial disparity focuses on the spatial variation of an accessibility value [36-38]. This value can be calculated based on the 2SFCA method, the implementation of which is often dependent on GIS-based mapping and visualization to identify high or low access regions. However, the 2SFCA method only calculates the value of access; the patterns of spatial variation in the accessibility value cannot always be found and tested. Therefore, this study integrates both 2SFCA method and spatial autocorrelation analysis to measure disparities in access to UGS in Harbin. Not only can these approaches calculate spatial accessibility, but spatial autocorrelation analysis can also test the distribution pattern of disparities and identify high- and low-value clusters. In contrast, studies of population disparity primarily investigate differences in access to UGSs between demographic, racial, social, and economic groups [27, 39, 40]. Racial and ethnic disparities in green space access are widely measured in western contexts because of their racial diversity. However, for countries such as China, which is highly racially homogenous, demographic disparities in UGS access are a greater concern. Therefore, this study focuses on exploring the demographic characteristics associated with accessibility.

Many similar studies that measure spatial or population disparities were conducted in developed countries, particularly in America [36]. However, very few studies have been conducted on that topic in developing countries such as China, and those that exist have focused on studying Southern Chinese cities (i.e., Xing et al. [39] and Li et al. [41]). Studies about Northern China, particularly about northeast Chinese cities, where there are less green infrastructure and greater concerns about UGS access than in the south, have rarely been conducted. Few studies about green spaces in Northeastern Chinese cities have focused on the cooling effects of green spaces [42], and there were still gaps in the research literature on disparities in UGS access. Therefore, this study will pay close attention to one of the representative cities in Northeast China, Harbin. The city has typical urban and sociodemographic characteristics of a Northeastern Chinese city including the spatial identity of industrial cities and urban aging, which makes it a representative case to conduct a survey. The aim of this study is to measure spatial and demographic disparities in UGS access in Harbin, China. There are two research objectives. First, we measured spatial accessibility to UGS using Gaussian-based 2SFCA to identify the distribution pattern of access values. Second, we investigated the correlative relationship between UGS access and demographic variables and evaluated the demographic disparities that urban inhabitants experience.

\section{Data and Methods}

2.1. Study Area. Harbin, the capital of Heilongjiang Province, is considered one of the political, cultural, and economic centers of Northeastern China. Since the administrative area of Harbin is very large, including two county-level cities, seven counties, and nine administrative districts, we selected the main urban area for investigation. The study area covers 94 residential tracts (Jiedao) in four administrative districts (Daoli, Daiwai, Nangang, and Xiangfang) and has a population of 2.86 million people according to the 2017 population census. Figure 1 presents the location of the study area; the northern part of the study 


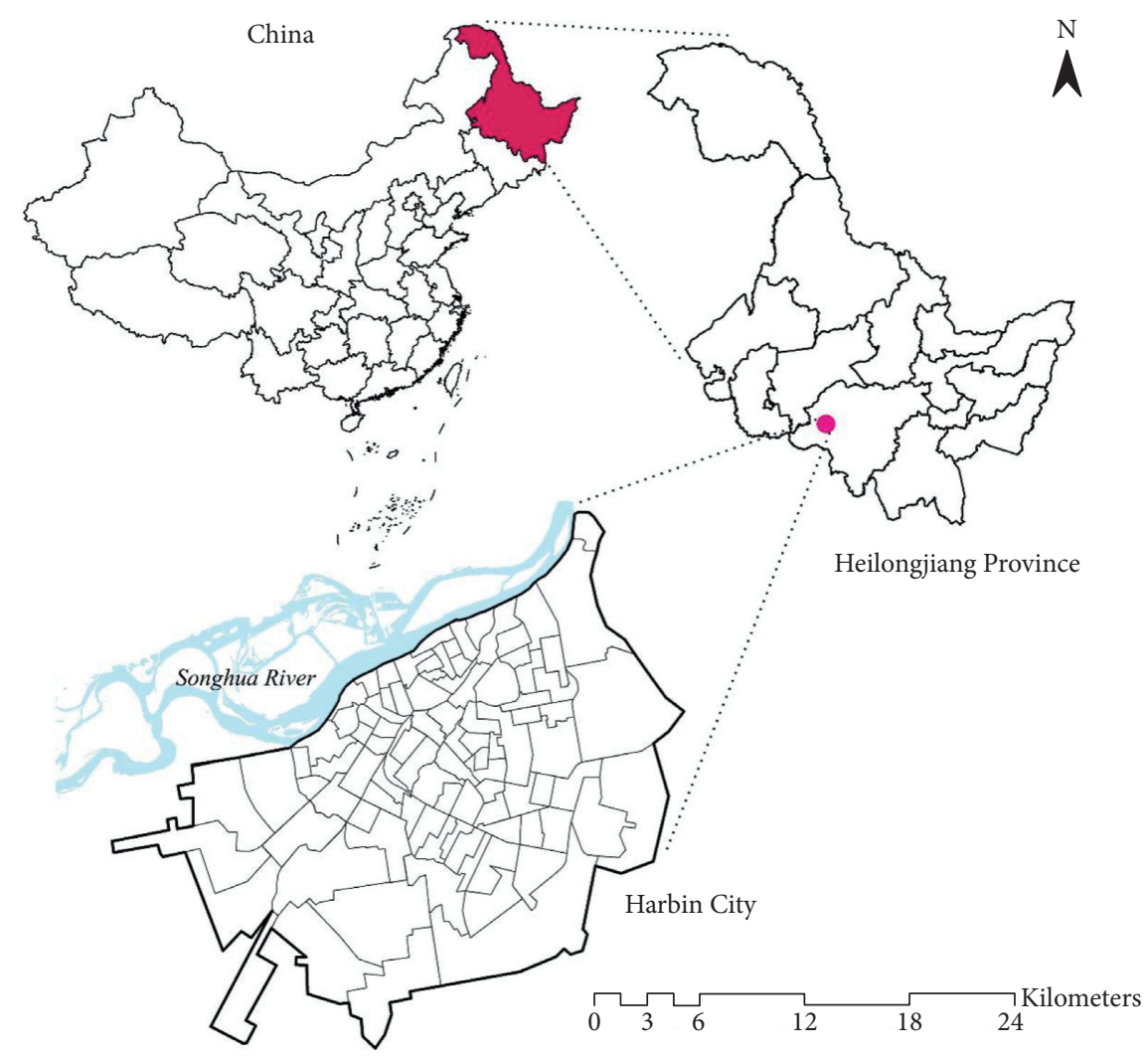

FIgURE 1: Location of the study area (Harbin City).

area is next to the Songhua River, known as one of China's seven major rivers. The other three regions in the area are linked to the rural-urban fringe.

2.2. Data Source and Processing. Population data based on the 2017 Harbin Census were obtained from the Harbin Natural Resource and Planning Administration, which collects data at city, district, and residential tract (Jiedao) levels. The residential tract serves as the minimum census tract and administrative division at subdistrict level, and its size generally contains several neighborhoods. The information pertaining to each residential tract includes total population, number of births per year, number of deaths per year, migration (number of inflows and outflows), and number of males and females. Based on this information, it is possible to measure the birth rate, mortality, sex ratio, immigration rate, and out-migration rate of each tract.

Meanwhile, 39 UGSs were selected in the study area based on three criteria: first, the UGS is available for various physical, social, and recreational activities; second, the UGS is accessible to the general public; third, the UGS is free of charge. The UGS data are mainly based on the Harbin land use survey conducted by the Harbin Natural Resource and Planning Administration and the vector data for the UGSs have been sourced from Baidu Maps (Baidu, Inc., 10 Shangdi 10th St., Haidian District, Beijing). The land use survey shows the distribution of all types of green spaces in the study area, which include not only the UGSs that people are able to access (such as comprehensive parks, theme parks, and recreation ground) but also the UGSs that are not accessible to the general public (such as private green space, roadside green space, and green buffer). Therefore, the Baidu Maps were used to identify the border of each selected UGS. As the size (acreage) of the green spaces is one of the crucial data in the study, to ensure the accuracy of the information from Baidu Maps, we conducted a three-week field survey in December 2019 to identify the actual border of each green space.

After collection, data on the UGSs and census tracts were integrated and converted to polygons using ESRI ArcGIS 10.5 (Environmental Systems Research Institute, Inc., 380 New York St., Redlands, CA). The acreage and population density of the polygons were also calculated using ArcGIS. A map of the study area was exported to present the population density of residential tracts $\left(\mathrm{pop} / \mathrm{km}^{2}\right)$ and the distribution of UGSs (Figure 2). Overall, higher population density tracts are clustered in the central urban region; peripheral regions in the west, south, and east regions of the urban area have comparatively low densities. UGSs are scattered throughout the study area with a generally random distribution pattern.

2.3. Measures of Spatial Accessibility between Demand and Supply. This study measures UGS access using the Gaussian-based 2SFCA technique, which is an intensified version of the original 2SFCA method proposed by two teams of scholars [29, 30]. This method is an integration of the 


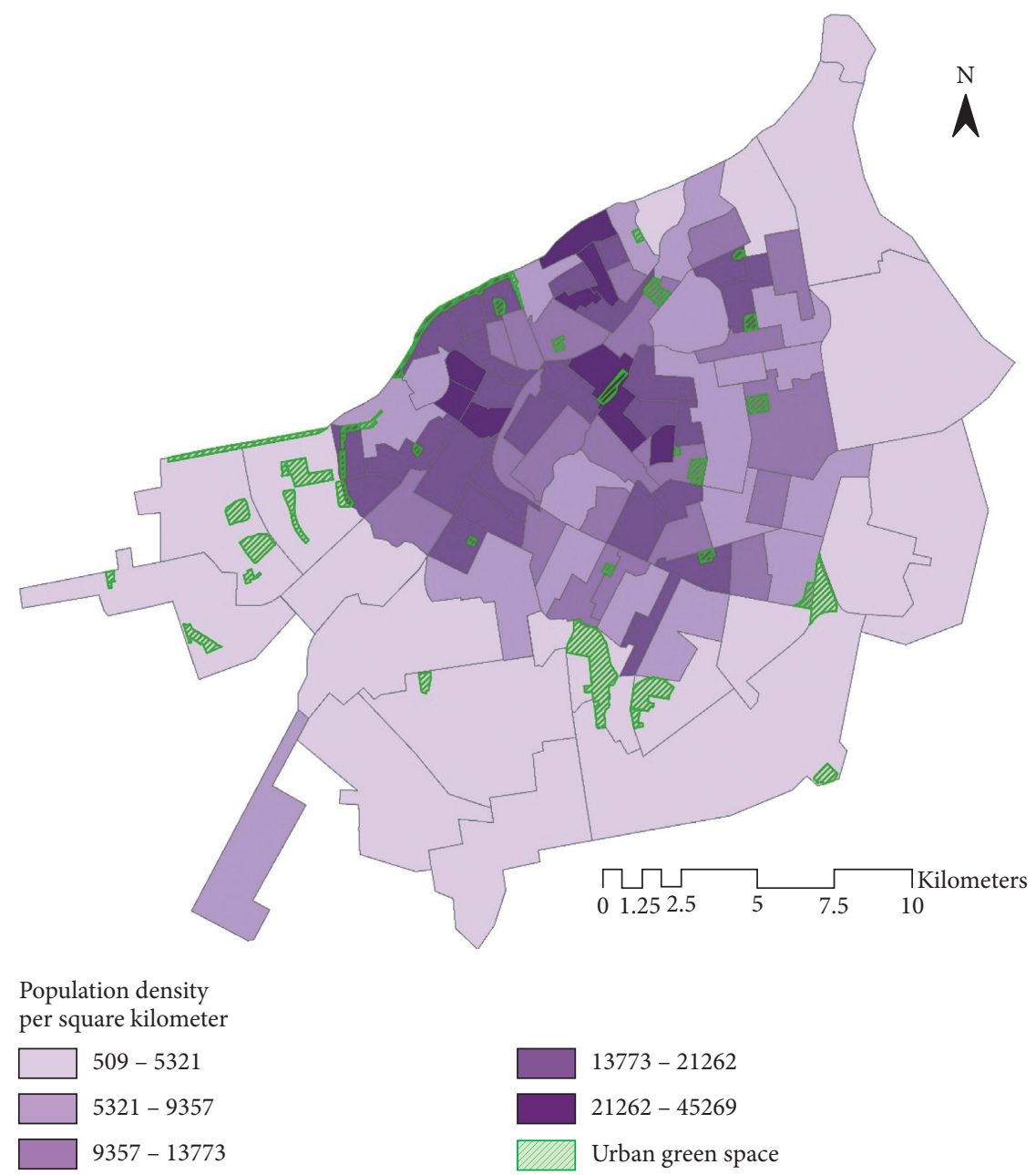

FIgURe 2: Population density of residential tracts and distribution of urban green spaces.

Gaussian function into the 2SFCA method, accounting for the "distance decay effect" of park services within a catchment area [36]. The distance decay effect, in this study, indicates the likelihood that the number of people visiting a UGS will decrease when the distance between them and UGSs increases. In comparison to the default position that visitation to UGS is equalized in the catchment, the distance decay function of a Gaussian-based 2SFCA method is more in accordance with the way people visit green spaces in real life.

Gaussian-based 2SFCA operations consist of two steps: calculating the supply-to-demand ratio of each UGS and measuring the accessibility value of each residential tract. In the first step, this study establishes a catchment area of green space $i$ based on threshold time $\left(t_{0}\right)$ and searches all demand locations (population tracts) $j$ within the catchment. The population at location $i$ is weighted by a Gaussian function $(G)$. The ratio $R$ of the UGS is calculated by summing all the weighted populations that fall into the catchment area. The equation can be written as follows:

$$
R_{i}=\frac{S_{i}}{\sum_{j \in\left\{t_{j i} \leq t_{0}\right\}} G\left(t_{j i}, t_{0}\right) P_{j}},
$$

where $S_{i}$ is the capacity of UGS supply at $i ; P_{j}$ is the population at residential tracts within the UGS catchment area $\left(t_{j i} \leq t_{0}\right) ; t_{j i}$ is the time cost from green space $i$ (location of supply) to population location $j$ (location of demand); $t_{0}$ is the threshold time, which determines the size of the UGS catchment area; and $G$ is the Gaussian function, which accounts for the distance decay effect of green space service. The function can be listed as follows:

$$
G\left(t_{j i}, t_{0}\right)= \begin{cases}\frac{e^{-(1 / 2) \times\left(t_{j i} / t_{0}\right)^{2}}-e^{-(1 / 2)}}{1-e^{-(1 / 2)},} & \text { if } t_{j i} \leq t_{0}, \\ 0, & \text { if } t_{j i}>t_{0} .\end{cases}
$$

In the second step of the Gaussian 2SFCA method, we generate a catchment of demand location (population tracts) $k$ based on the time threshold $\left(t_{0}\right)$ and search all the green spaces $l$ within the catchment area. Then, the Gaussian function $(G)$ is used to weight the ratio $R$ of each UGS; the accessibility value $(A)$ of the population tracts $k$ is calculated by summing all the weighted ratios $R$ within the catchment area, the equation for which is 


$$
A_{k}=\sum_{l \in\left\{t_{k l} \leq t_{0}\right\}} G\left(t_{k l}, t_{0}\right) R_{l},
$$

where $l$ is the UGS that falls within the catchment of demand location $k, R$ is the ratio of green space $l, G$ is the Gaussian function as described in (2), and the accessibility value $A_{k}$ denotes the amount of UGS (in square meters) per capita.

Catchment size is a crucial parameter in the Gaussian 2SFCA method for determining whether a residential tract can be considered near (accessible) a UGS. The threshold time (or threshold distance) $t_{0}$ between a UGS and a residential tract is the key variable for shaping the catchment size, which is defined by the mobility of park users. Mobility is differentiated from transportation modes, including walking, biking, driving, and public transit. In terms of accessibility to UGSs, active transportation (walking and cycling) is recommended because of the benefits they provide for one's health and the environment [36]. Thus, in this study, we established catchment size and threshold time based on walking and cycling modes.

This study selected four threshold walking times to define four types of UGS catchment sizes (CSs): $\mathrm{CS}_{1}$ $\left(t_{0}=7 \mathrm{~min}\right), \mathrm{CS}_{2}\left(t_{0}=15 \mathrm{~min}\right), \mathrm{CS}_{3}\left(t_{0}=20 \mathrm{~min}\right)$, and $\mathrm{CS}_{4}$ $\left(t_{0}=30 \mathrm{~min}\right)$. Different catchment sizes represent different mobility patterns. $\mathrm{CS}_{1}$ and $\mathrm{CS}_{2}$ (range of time cost from 0 to $15 \mathrm{~min}$ ) represent regular walking distance to access a UGS, and $\mathrm{CS}_{3}$ and $\mathrm{CS}_{4}$, where the range of time cost is greater than $15 \mathrm{~min}$, represent a long walking or cycling distance.

\section{Results}

3.1. Spatial Disparities in Accessibility. This study measures spatial disparities in accessibility across the four catchment sizes using a Gaussian 2SFCA. The results of the accessibility values were visualized using the exported ArcGIS maps (Figure 3), for which we employed a quantile method to classify the value. The four maps show UGS accessibility corresponding to $\mathrm{CS}_{1}, \mathrm{CS}_{2}, \mathrm{CS}_{3}$, and $\mathrm{CS}_{4}$. The values of accessibility signify the quantity of UGS (area in $\mathrm{m}^{2}$ ) per capita, which varies from 0 to 82.39 throughout the study area.

According to Figure $3(\mathrm{a})$, when $t_{0}=7 \mathrm{~min}$, the majority of residential areas have a low accessibility to UGS. In contrast, a few residential tracts with great accessibility are scattered in the central and western urban areas, some of which have considerably high accessibility values (over $80 \mathrm{~m}^{2} /$ pop.). When $t_{0}=15 \mathrm{~min}$ (Figure $3(\mathrm{~b})$ ), a few residential tracts show an increase in accessibility, and residential areas with comparatively higher accessibility values tend to gather in the southwest. However, the vast majority of regions remain access-disadvantaged; when $t_{0}=20 \mathrm{~min}$ (Figure 3(c)), more tracts have improved levels of accessibility. Residential areas with relatively greater access nearly form a ring around the central city; when $t_{0}=30 \mathrm{~min}$ (Figure 3(d)), approximately half of the residential tracts show a clear improvement in access to UGS; however, the other half remain much less accessible. Tracts with comparatively greater access surround the central city in a cyclic annular, and high-access tracts are located mainly in western and southern suburbs.

\subsection{Testing the Spatial Distribution Pattern of Accessibility.} Although Figure 3 provides information about access disparities in the study area, the tendency and pattern of the distribution remain unclear and untested. Therefore, in this section, we use spatial autocorrelation to evaluate the distribution of accessibility, which can determine whether selected objects correlate with the surrounding objects in value [43]. Moran's $I$ is a commonly used approach to test global spatial autocorrelation $[44,45]$. Positive and negative Moran's I indexes correspond, respectively, to a clustered and a dispersed distribution of objects, except when the test accepts the null hypothesis $\left(H_{0}\right)$, which indicates that the distribution pattern is random. The $z$-score and $p$ value in the test are used to determine whether the alternative hypothesis $\left(H_{A}\right)$ should be accepted.

This study uses Moran's $I$ to test the distribution of accessibility $^{\mathrm{a}-\mathrm{d}}$ (Table 1). The results show that $H_{A}$ is rejected when $t_{0}$ equals $7 \mathrm{~min}, 15 \mathrm{~min}$, or $20 \mathrm{~min}$, which indicates that the distribution of accessibility is random in these three cases. Only when $t_{0}$ equals $30 \mathrm{~min}$ is the result statistically significant. Because of positive Moran's I index, the accessibility associated with the residential tracts tends to be a clustered distribution.

Global measures of spatial autocorrelation (Moran's I) investigate the distribution of the access value as a whole within the study area (at the global level) and are not able to provide information about local spatial dependencies. Therefore, this study undertakes hot spot analysis (GetisOrd $G i^{*}$ ), a local spatial autocorrelation tool offered by Getis and Ord [46], to further identify local clusters in the study area. We conducted an analysis of the distribution of accessibility when $t_{0}$ equals $30 \mathrm{~min}$, which is statistically significant in the measure of spatial autocorrelation. In the Getis-Ord $G i^{*}$ method, a $\mathrm{z}$-score is calculated for each residential tract, and a significant $z$-score with a high positive value indicates that local clusters of tracts are associated with high-access values (hot spot). In contrast, a significant $\mathrm{z}$-score with a low and negative score value denotes a clustering of low accessibility values (cold spot). Based on the $z$-score, the statistical significance is divided into three confidence levels (90\%, 95\%, and 99\% confidence).

Figure 4 presents the results of Getis-Ord $\mathrm{Gi}^{*}$ analysis, which clearly identifies cold spots and hot spots of accessibility. The significant spatial clusters of residential tracts with a low accessibility value (cold spot) are located in the center of the research area. In contrast, significant clusters of residential tracts with a high accessibility value (hot spot) were located in northern and western suburbs. The results of other regions of the study area have no statistical significance in Getis-Ord $G i^{*}$ analysis. In general, within the study area, the tracts with low accessibility to UGS tend to cluster in the middle of the city, while high-accessibility areas tend to be located on the urban fringes. 


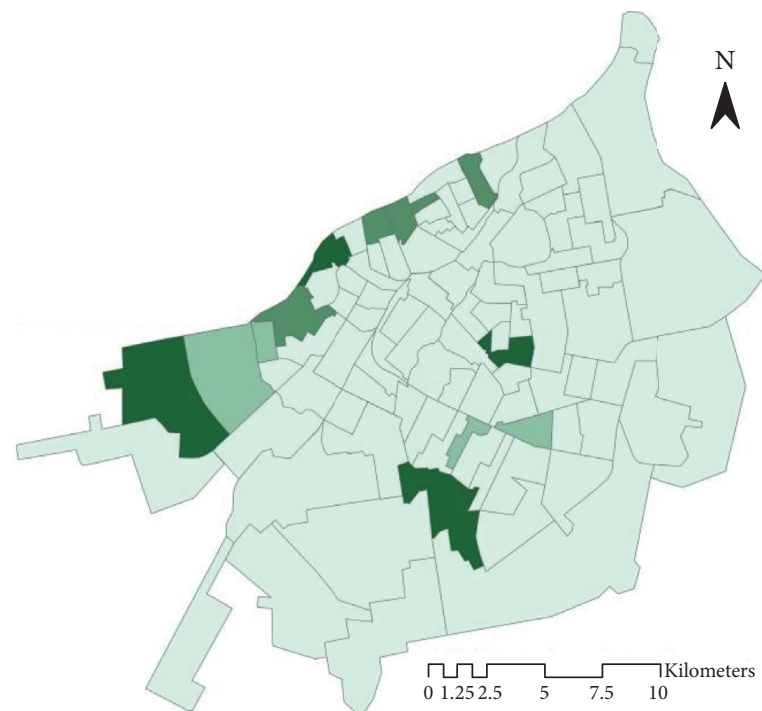

Accessibility $\mathrm{CS}_{1} t_{0}=7 \mathrm{~min}$

$0.00-2.91$

$2.91-4.94$

(a)

(a)

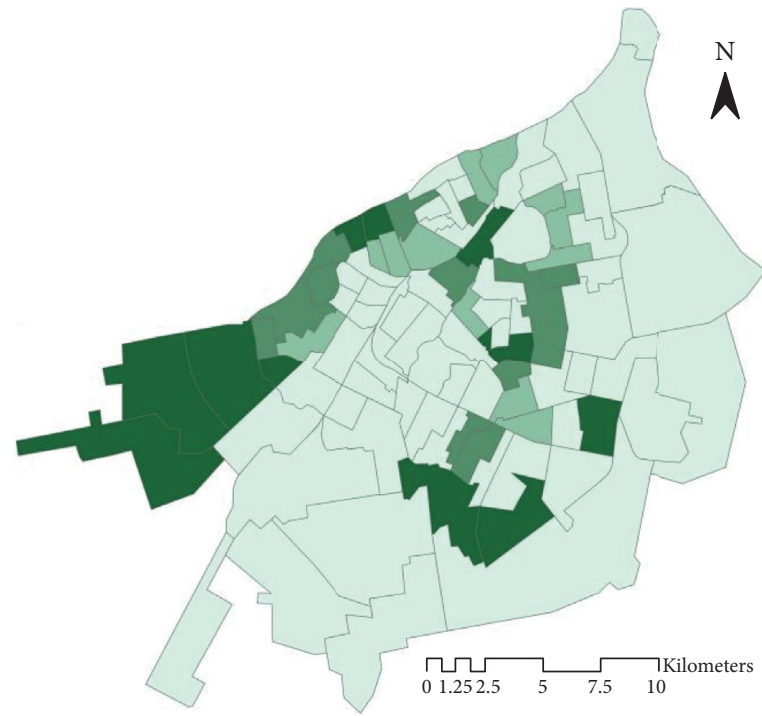

Accessibility

$\mathrm{CS}_{3} t_{0}=20 \mathrm{~min}$

$$
\begin{aligned}
& 0.00-1.27 \\
& 1.27-2.91
\end{aligned}
$$

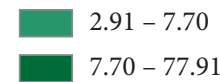

(c)

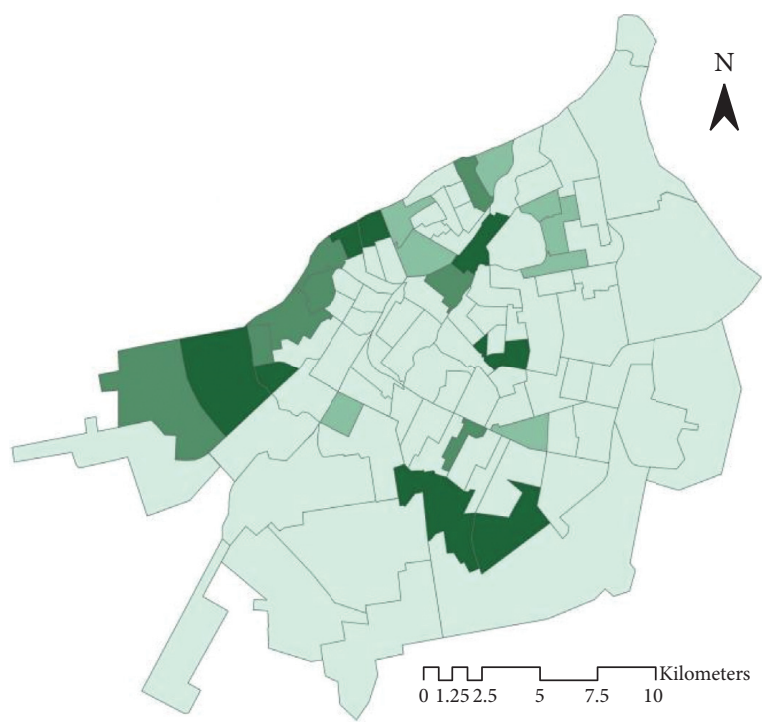

Accessibility

$\mathrm{CS}_{2} t_{0}=15 \mathrm{~min}$

$0.00-1.34$
$1.34-3.53$

$3.53-8.82$

$8.82-82.39$

(b)

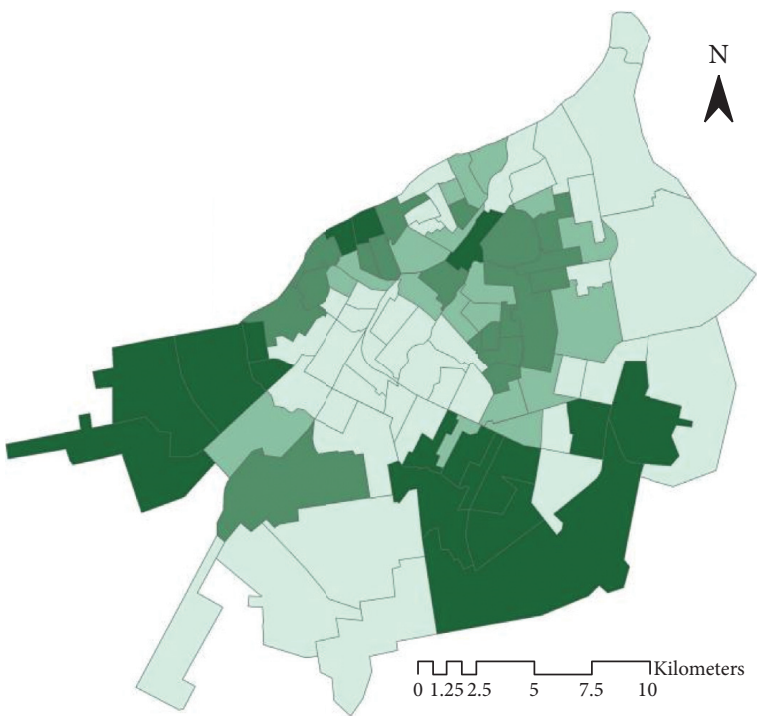

Accessibility

$\mathrm{CS}_{4} t_{0}=30 \mathrm{~min}$

$0.00-0.943$

$0.943-2.01$
$2.01-5.57$

$5.57-38.04$

(d)

Figure 3: Spatial accessibility to urban green spaces in Harbin $\left(t_{0}=7 \mathrm{~min} ; t_{0}=15 \mathrm{~min} ; t_{0}=20 \mathrm{~min} ; t_{0}=30 \mathrm{~min}\right)$.

3.3. Evaluating Demographic Disparities in Accessibility. In this section, we attempt to evaluate the demographic disparities by exploring the statistical relationship between demographic characteristics of residential tracts and accessibility to UGS. Bivariate correlation was undertaken to examine accessibility $^{\mathrm{a}-\mathrm{d}}\left(t_{0}=7,15,20\right.$, and $\left.30 \mathrm{~min}\right)$ with each of the eight demographic variables, including population of children under 17 (\%),population of elderly individuals over $60(\%)$, birth rate (\%o), mortality rate (\%o), sex ratio, rate of immigration, rate of out-migration, and population density.

Table 2 presents the results of bivariate correlation analysis. First, the sex ratio of residential tracts shows a significant negative correlation with accessibility ${ }^{\mathrm{d}}$ at a level of 0.01 . Because of the way sex ratio is calculated in this instance (females divided by males), the female ratio is 
TABLe 1: Moran's I for accessibility (when $t_{0}$ equals $7 \mathrm{~min}, 15 \mathrm{~min}, 20 \mathrm{~min}$, and $30 \mathrm{~min}$ ).

\begin{tabular}{|c|c|c|c|c|}
\hline Accessibility to UGS & Moran's I index & $Z$-score & $p$ value & Distribution \\
\hline Accessibility $^{\mathrm{a}}, \mathrm{CS}_{1}, t_{0}=7 \mathrm{~min}$ & 0.00 & 0.66 & 0.51 & Random $\left(H_{0}\right)$ \\
\hline Accessibility ${ }^{\mathrm{b}}, \mathrm{CS}_{2}, t_{0}=15 \mathrm{~min}$ & 0.03 & 1.61 & 0.11 & Random $\left(H_{0}\right)$ \\
\hline Accessibility ${ }^{\mathrm{c}}, \mathrm{CS}_{3}, t_{0}=20 \mathrm{~min}$ & 0.03 & 1.44 & 0.15 & Random $\left(H_{0}\right)$ \\
\hline Accessibility ${ }^{\mathrm{d}}, \mathrm{CS}_{4}, t_{0}=30 \mathrm{~min}$ & 0.14 & 4.81 & 0.00 & Clustered $\left(H_{A}\right)$ \\
\hline
\end{tabular}

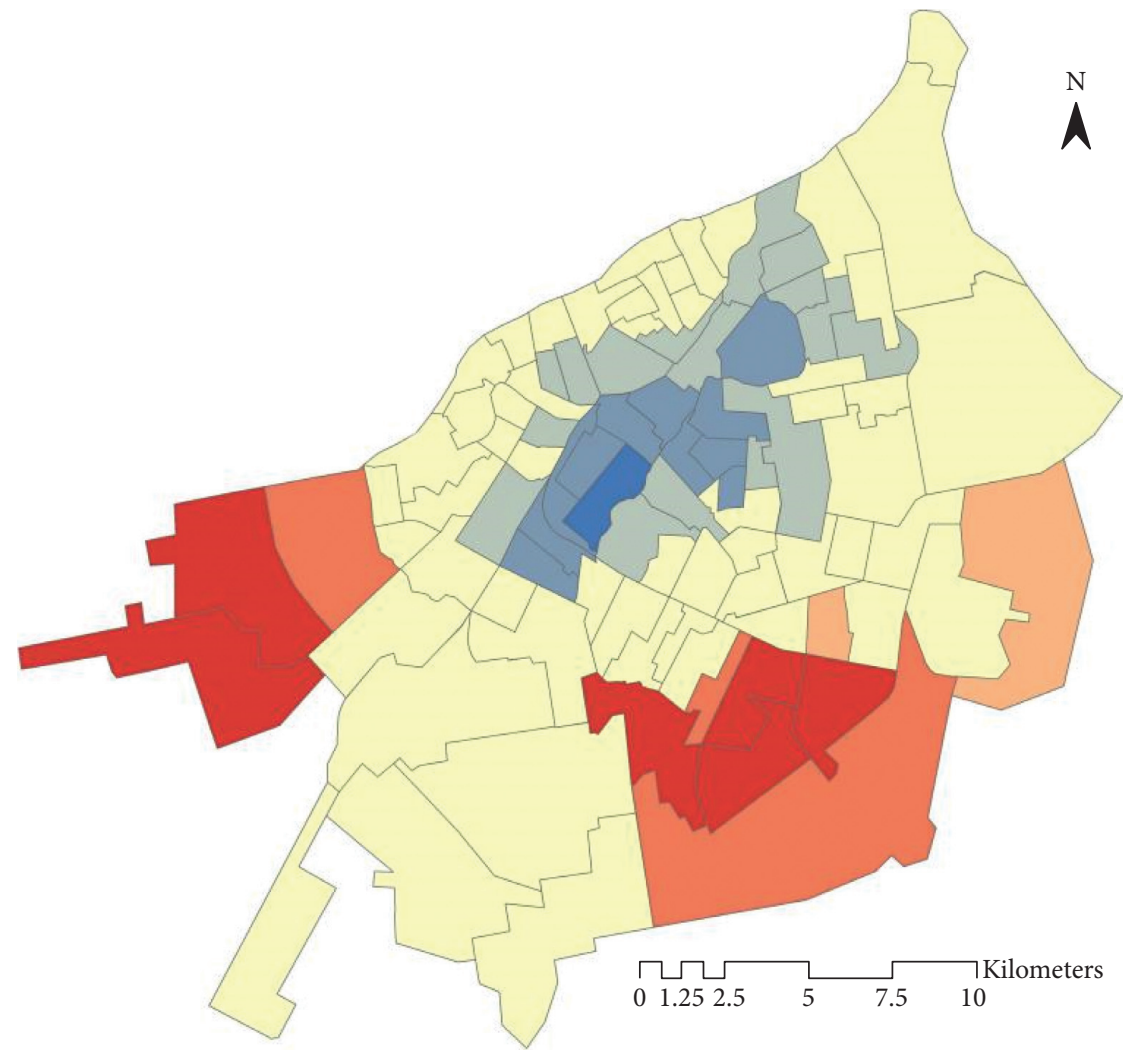

Getis-Ord Gi*

Accessbility $\left(t_{0}=30 \mathrm{~min}\right)$
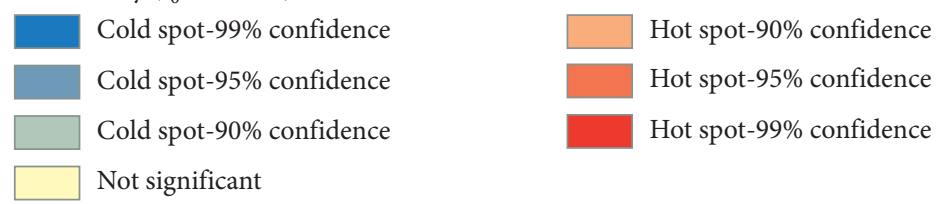

FIgURE 4: Hot spot analysis (Getis-Ord $\left.G i^{*}\right)$ of accessibility ${ }^{\mathrm{d}}\left(t_{0}=30 \mathrm{~min}\right)$ associated with residential tracts.

inversely proportional to accessibility ${ }^{\mathrm{d}}$. Moreover, we found that birth rate is positively associated with accessibilty ${ }^{\mathrm{b}}$, accessibility $^{c}$, and accessibility ${ }^{\mathrm{d}}$ with significant levels of $0.05,0.05$, and 0.01 , respectively, which indicates that as birth rate increases, accessibilty ${ }^{\mathrm{b}-\mathrm{d}}$ increase. In contrast, accessibilty $^{\mathrm{b}-\mathrm{d}}$ are all negatively correlated with population density, and the significance levels are $0.05,0.01$, and 0.01 , respectively. In addition, other demographic variables related to age and migration, including population of children under 17 , population of elderly above 60 , rate of immigration, and rate of out-migration, do not have a statistically significant relationship with any of the indicators of accessibility.

\section{Discussion}

This study used a Gaussian-based 2SFCA method to measure spatial access to UGSs based on four threshold walking times $(7,15,20$, and $30 \mathrm{~min}$ ). (i) A 7 min walk (approximately $500 \mathrm{~m}$ ) is defined as "walking distance" by some researchers $[15,23]$. However, this study observed that, within a 7 min catchment area, the available amount of UGS for the majority of the residential areas was under $3 \mathrm{~m}^{2}$ per person, much lower than the $9 \mathrm{~m}^{2}$ per person advocated by the WHO [47-49]. (ii) A $15 \mathrm{~min}$ walk (approximately $1,000 \mathrm{~m}$ ) is considered the critical walking distance to access a park $[24,25,28,50]$ because when people want to reach a 
TABLE 2: Bivariate correlation between accessibility and demographic variables.

\begin{tabular}{|c|c|c|c|c|}
\hline $\begin{array}{l}\text { Demographic } \\
\text { variables }\end{array}$ & Accessibility $^{\mathrm{a}}\left(t_{0}=7 \mathrm{~min}\right)$ & Accessibility $^{\mathrm{b}}\left(t_{0}=15 \mathrm{~min}\right)$ & $\operatorname{Accessibility~}^{\mathrm{c}}\left(t_{0}=20 \mathrm{~min}\right)$ & Accessibility $^{\mathrm{d}}\left(t_{0}=30 \mathrm{~min}\right)$ \\
\hline \multicolumn{5}{|l|}{ Age } \\
\hline $\begin{array}{l}\text { Pop. of children } \\
\text { under } 17(\%)\end{array}$ & 0.105 & 0.099 & 0.012 & 0.093 \\
\hline $\begin{array}{l}\text { Pop. of elderly } \\
\text { above } 60(\%)\end{array}$ & -0.213 & -0.138 & -0.111 & -0.194 \\
\hline \multicolumn{5}{|l|}{ Gender } \\
\hline $\begin{array}{l}\text { Sex ratio (females/ } \\
\text { males) }\end{array}$ & -0.315 & -0.282 & -0.179 & $-0.369^{* *}$ \\
\hline \multicolumn{5}{|l|}{ Natural increase in pop. } \\
\hline Birth rate $(\% o)$ & 0.336 & $0.350^{*}$ & $0.353^{*}$ & $0.437^{* *}$ \\
\hline Mortality rate $(\%)$ & 0.019 & 0.006 & 0.047 & -0.077 \\
\hline \multicolumn{5}{|l|}{ Migration } \\
\hline $\begin{array}{l}\text { Rate of } \\
\text { immigration (\%) }\end{array}$ & -0.043 & -0.122 & -0.108 & -0.130 \\
\hline $\begin{array}{l}\text { Rate of out- } \\
\text { migration (\%) }\end{array}$ & 0.280 & 0.277 & 0.181 & 0.190 \\
\hline \multicolumn{5}{|l|}{ Density } \\
\hline $\begin{array}{l}\text { Population density } \\
\left.\text { (pop. } / \mathrm{m}^{2}\right)\end{array}$ & -0.425 & $-0.432^{*}$ & $-0.422^{* *}$ & $-0.403^{* *}$ \\
\hline
\end{tabular}

UGS at a greater distance, they choose transportation modes other than walking. However, even when threshold time is increased to $15 \mathrm{~min}$, only a few residential tracts can achieve a $3.5 \mathrm{~m}^{2}$ of UGS per person. The 7 and $15 \mathrm{~min}$ catchments accord with walking distance to a UGS; therefore, in general, UGSs in Harbin urban areas are not walking friendly. The supply of green space must be improved in terms of amount and acreage, especially within a short walking distance from citizens' residences. The catchment sizes of $20 \mathrm{~min}$ and $30 \mathrm{~min}$ accord with the transportation modes of long-distance walking, running, or cycling. (iii) A 20 min catchment (approximately 1,300 m) has been defined as "cycling distance" by previous researchers [51]. In this study, even though a number of the residential tracts have experienced an increase in access value, more than half of the tracts still have disadvantages in terms of accessibility to UGS. (iv) When it comes to a $30 \mathrm{~min}$ catchment, which is nearly the critical distance for cycling, half of the study area has much less access to UGS. Generally speaking, for active transportation modes, such as walking and cycling, many areas of Harbin contain very limited amounts of green space.

The spatial distribution of accessibility can reflect the uneven or unequal distribution of UGS, and this urban problem can be found in many cities worldwide [52]. In this study, accessibility is randomly distributed when the threshold time is less than $20 \mathrm{~min}$. This might be because of the very small number of residential tracts with high accessibility, which are generally distributed in the city with no clear pattern. In contrast, the number of tracts with high-value accessibility dramatically increases when the threshold time is $30 \mathrm{~min}$. At this point, the distribution of accessibility is clustered according to the results of Moran's I test, and hot spot analysis also indicates that low accessibility tracts are located in the center of the study area, while high accessibility tracts tend to cluster on urban fringes, especially in northern and southern suburbs. On the contrary, the middle of the city has a higher density than the surrounding suburbs according to the population density map (Figure 2). This indicates an uneven distribution and a disproportionate supply of UGS for urban inhabitants.

Previous studies have ascertained that many sociodemographic characteristics are associated with park use [53] and disparities in the supply of UGS occur with demographic and racial differences [54]. This study also explored the relationship between demographic indicators and accessibility to UGS. Because of the dissimilarity between the research method and urban context, the results in this paper differ from those in the others $[55,56]$.

(i) In terms of gender, very few studies examine the correlation between sex ratio and green space access. One such study was conducted in Brisbane, Australia, which found no significant relationships between the two [55]. However, in the case of Harbin, we found that gender is correlated with accessibility (a $30 \mathrm{~min}$ walk) to UGS, where the proportion of females is negatively associated with green space access. This indicates that, for long walking or cycling distances, females have more disadvantages in accessing green spaces than males in the city.

(ii) Previous studies have mentioned the relationship between lack of access and mortality [56]. However, significant correlations between the two were not observed in this study. In contrast, the birth rate, the demographic indicator that relevant studies rarely pay attention to, is found to have a significant positive correlation with UGS accessibility in Harbin, which reflects that, for high birth rate areas, people tend to have greater green space access than in other 
areas in the city. Even though it is difficult to explain this association, we still infer that newlyweds might have an advantage in access to UGSs. In China, marriage is one of the strongest motivations for housing consumption, and newlyweds are one of the primary groups that purchase an additional house [57]. Therefore, in comparison to other social groups, newlyweds will have greater opportunities to choose houses with greater location advantages and higher UGSs accessibility. However, this is an inferential point of view by this study, and further empirical studies are needed to confirm the inference.

(iii) The correlation test demonstrates that density has a negative association with accessibility when the threshold time is greater than or equal to $15 \mathrm{~min}$. This indicates that more populated regions have less access to UGS in the study area, which is consistent with the information from hot spot analysis above. Highdensity areas in Harbin are mainly found in the central parts of the city, where there is a very limited amount of space for UGS provision. In comparison, low density area in suburbs provides more space for building UGSs, and the people there can access more UGSs than those who live in the middle of the city. However, this situation is not unique, as many studies have indicated that denser urban areas have fewer green spaces $[11,58]$. Since areas with higher density reflect a greater need for UGS $[59,60]$, the result yields a problem of spatial disparity between population demand and UGS supply.

(iv) This study found no significant correlation between age and access to UGS, which indicates that residential tracts with a high proportion of elderly or children do not take more advantage of their access to green spaces in Harbin than others do. In fact, "compensatory equity" suggests that public benefits (such as UGS) should be consistent with need [61, 62] and previous studies have identified that the elderly and children are the disadvantaged groups with the greater need of access to green spaces [63-65]. Provinces in Northeast China have experienced rapid population aging [66]. In Harbin, one of the capital cities in Northeast China, population aging is always a severe issue. According to the 2017 population census, the proportion of people over 60 is $24.9 \%$ within the study area, and in some residential tracts, this proportion is even as high as $39.5 \%$. This indicates that seniors in Harbin have high demands for the improvement of access to UGSs. Therefore, this paper suggests that Harbin should concentrate on the needs of seniors and other high-demand groups when planning green space provision.

This study provides several recommendations to Harbin and other similar Northeastern Chinese cities regarding UGS provisions and interventions to enhance the equity and adequacy. First, Harbin should increase UGS supply in a walking or cycling distance, which promotes the frequency of UGS use; in addition, active transportation modes also help improve the level of physical activity and well-being of its citizens. Second, Harbin provide greater numbers of UGS to the inner city, where accessibility is relatively low. However, available spaces in the compact inner city for UGS are always limited, so we suggest the implementation of strategies such as mixed-use UGS and rooftop green spaces for optimized space utilization. Third, UGS provision strategies should also focus on disparities between demand and supply. The disparities can be both spatial and demographic; thus, not only more UGSs should be provided to the high density residential areas to meet the greater demand, but the supply strategies should also be devised based on the social and demographic composition in the areas.

\section{Conclusions}

In conclusion, this study first measured access disparities to UGSs in urban areas of Harbin. In general, the majority of residential areas have much less walking distance UGS access. As regards cycling distance access, even if the access value is enhanced in many areas, a number of residential tracts still cannot meet WHO standards. Furthermore, the result of spatial autocorrelation tests indicates an uneven distribution and a disproportionate provision of UGS to urban residents. Second, this study evaluated the demographic disparities by exploring the statistical relationship between eight demographic indicators of residential area and UGS access with four threshold times. The results show that gender, birth rate, and population density have a significant correlation with green space access, with females in the study having less access than males, areas with high birth rates having more access to UGS, and with population density being negatively associated with UGS access. The findings identify which areas and population groups are disadvantaged, which should help advise policy-makers on future construction and provision of UGS.

\section{Data Availability}

The data used to support the findings of this study are available from the corresponding author upon request.

\section{Conflicts of Interest}

The authors declare that there are no conflicts of interest.

\section{Acknowledgments}

This study was supported by the National Natural Science Foundation of China (Grant no. 52078160) and the National Key Research and Development Program of China (Grant no. 2018YFC0704705).

\section{References}

[1] A. T. Kaczynski and K. A. Henderson, "Parks and recreation settings and active living: a review of associations with 
physical activity function and intensity," Journal of Physical Activity and Health, vol. 5, no. 4, pp. 619-632, 2008.

[2] J. R. Wolch, J. Byrne, and J. P. Newell, "Urban green space, public health, and environmental justice: the challenge of making cities "just green enough"” Landscape and Urban Planning, vol. 125, pp. 234-244, 2014.

[3] A. Chiesura, "The role of urban parks for the sustainable city," Landscape and Urban Planning, vol. 68, no. 1, pp. 129-138, 2004.

[4] L. R. Larson, V. Jennings, and S. A. Cloutier, "Public parks and wellbeing in urban areas of the United States," PLoS One, vol. 11, no. 4, pp. 1-19, 2016.

[5] C. L. Ogden, M. D. Carroll, and K. M. Flegal, "High body mass index for age among US children and adolescents, 2003-2006," Jama, vol. 299, no. 20, pp. 2401-2405, 2008.

[6] P. Grahn and U. K. Stigsdotter, "The relation between perceived sensory dimensions of urban green space and stress restoration," Landscape and Urban Planning, vol. 94, no. 3-4, pp. 264-275, 2010.

[7] G. R. McCormack, M. Rock, A. M. Toohey, and D. Hignell, "Characteristics of urban parks associated with park use and physical activity: a review of qualitative research," Health \& Place, vol. 16, no. 4, pp. 712-726, 2010.

[8] J. Yang, J. Sun, Q. Ge, and X. Li, “Assessing the impacts of urbanization-associated green space on urban land surface temperature: a case study of Dalian, China," Urban Forestry \& Urban Greening, vol. 22, pp. 1-10, 2017.

[9] J. Yang, Y. Guan, J. Xia, C. Jin, and X. Li, "Spatiotemporal variation characteristics of green space ecosystem service value at urban fringes: a case study on Ganjingzi district in Dalian, China," Science of the Total Environment, vol. 639, pp. 1453-1461, 2018.

[10] A. Rigolon, "A complex landscape of inequity in access to urban parks: a literature review," Landscape and Urban Planning, vol. 153, pp. 160-169, 2016.

[11] C. G. Boone, G. L. Buckley, J. M. Grove, and C. Sister, "Parks and people: an environmental justice inquiry in Baltimore, Maryland," Annals of the Association of American Geographers, vol. 99, no. 4, pp. 767-787, 2009.

[12] C. Boulton, A. Dedekorkut-Howes, and J. Byrne, "Factors shaping urban greenspace provision: a systematic review of the literature," Landscape and Urban Planning, vol. 178, pp. 82-101, 2018.

[13] C. Sister, J. Wolch, and J. Wilson, "Got green? addressing environmental justice in park provision," GeoJournal, vol. 75, no. 3, pp. 229-248, 2010.

[14] L. Willemse, "A flowmap-geographic information systems approach to determine community neighbourhood park proximity in Cape Town," South African Geographical Journal, vol. 95, no. 2, pp. 149-164, 2013.

[15] H. Wüstemann, D. Kalisch, and J. Kolbe, "Access to urban green space and environmental inequalities in Germany," Landscape and Urban Planning, vol. 164, pp. 124-131, 2017.

[16] C. Schwarte and M. Adebowale, Environmental Justice and Race Equality in the European Union, London, Capacity Global, London, UK, 2007.

[17] N. Kabisch and D. Haase, "Green justice or just green? Provision of urban green spaces in Berlin, Germany," Landscape and Urban Planning, vol. 122, pp. 129-139, 2014.

[18] P. Y. Tan and R. Samsudin, "Effects of spatial scale on assessment of spatial equity of urban park provision," Landscape and Urban Planning, vol. 158, pp. 139-154, 2017.

[19] C. M. Raymond, S. Gottwald, J. Kuoppa, and M. Kyttä, "Integrating multiple elements of environmental justice into urban blue space planning using public participation geographic information systems," Landscape and Urban Planning, vol. 153, pp. 198-208, 2016.

[20] A. T. Kaczynski and K. A. Henderson, "Environmental correlates of physical activity: a review of evidence about parks and recreation," Leisure Sciences, vol. 29, no. 4, pp. 315-354, 2007.

[21] S. Guo, G. Yang, T. Pei et al., "Analysis of factors affecting urban park service area in Beijing: perspectives from multi-source geographic data," Landscape and Urban Planning, vol. 181, pp. 103-117, 2019.

[22] H. Millward, J. Spinney, and D. Scott, "Active-transport walking behavior: destinations, durations, distances," Journal of Transport Geography, vol. 28, pp. 101-110, 2013.

[23] R. Boyle, Survey of the Use of Small Parks, Australian Parks and Recreation, Berlin, Germany, 1983.

[24] D. Stanners and P. Bourdeau, "The urban environment," in Europe's Environment: The Dobris Assessment, D. Stanners and P. Bourdeau, Eds., European Environment Agency, Copenhagen, Denmark, 1995.

[25] P. Harnik and A. Martin, Close-to-Home Parks: A Half-Mile or Less, Center for City Park Excellence, Trust for Public Land, Washington, DC, USA, 2012.

[26] T.-T.-H. Pham, D. Labbé, U. Lachapelle, and É. Pelletier, "Perception of park access and park use amongst youth in Hanoi: how cultural and local context matters," Landscape and Urban Planning, vol. 189, pp. 156-165, 2019.

[27] H. E. Wright Wendel, R. K. Zarger, and J. R. Mihelcic, "Accessibility and usability: green space preferences, perceptions, and barriers in a rapidly urbanizing city in Latin America," Landscape and Urban Planning, vol. 107, no. 3, pp. 272-282, 2012.

[28] T.-T.-H. Pham and D. Labbé, "Spatial logic and the distribution of open and green public spaces in hanoi: planning in a dense and rapidly changing city," Urban Policy and Research, vol. 36, no. 2, pp. 168-185, 2017.

[29] J. Radke and L. Mu, "Spatial decompositions, modeling and mapping service regions to predict access to social programs," Annals of GIS, vol. 6, no. 2, pp. 105-112, 2000.

[30] W. Luo and F. Wang, "Measures of spatial accessibility to health care in a GIS environment: synthesis and a case study in the chicago region," Environment and Planning B: Planning and Design, vol. 30, no. 6, pp. 865-884, 2003.

[31] W. Luo and Y. Qi, "An enhanced two-step floating catchment area (E2SFCA) method for measuring spatial accessibility to primary care physicians," Health \& Place, vol. 15, no. 4, pp. 1100-1107, 2009.

[32] D. Dai, "Black residential segregation, disparities in spatial access to health care facilities, and late-stage breast cancer diagnosis in metropolitan Detroit," Health \& Place, vol. 16, no. 5, pp. 1038-1052, 2010.

[33] W. Luo and T. Whippo, "Variable catchment sizes for the two-step floating catchment area (2SFCA) method," Health \& Place, vol. 18, no. 4, pp. 789-795, 2012.

[34] D. Dai and F. Wang, "Geographic disparities in accessibility to food stores in southwest Mississippi," Environment and Planning B: Planning and Design, vol. 38, no. 4, pp. 659-677, 2011.

[35] J. Wu, Z. Cai, and H. Li, "Accessibility of medical facilities in multiple traffic modes: a study in Guangzhou, China," Complexity, vol. 2020, Article ID 8819836, , 2020.

[36] D. Dai, "Racial/ethnic and socioeconomic disparities in urban green space accessibility: where to intervene?" Landscape and Urban Planning, vol. 102, no. 4, pp. 234-244, 2011. 
[37] J. Macedo and M. A. Haddad, "Equitable distribution of open space: using spatial analysis to evaluate urban parks in Curitiba," Brazil," Environment and Planning B: Planning and Design, vol. 43, no. 6, pp. 1096-1117, 2015.

[38] G. Lee and I. Hong, "Measuring spatial accessibility in the context of spatial disparity between demand and supply of urban park service," Landscape and Urban Planning, vol. 119, pp. 85-90, 2013.

[39] L. Xing, Y. Liu, X. Liu, X. Wei, and Y. Mao, "Spatio-temporal disparity between demand and supply of park green space service in urban area of Wuhan from 2000 to 2014," Habitat International, vol. 71, pp. 49-59, 2018.

[40] D. T. Duncan, I. Kawachi, K. White, and D. R. Williams, "The geography of recreational open space: influence of neighborhood racial composition and neighborhood poverty fluence of neighborhood racial composition and neighborhood poverty," Journal of Urban Health, vol. 90, no. 4, pp. 618-631, 2013.

[41] X. Li, X. Ma, X. Xue, and M. H. Khuong, "Spatial supplydemand evaluation and layout optimization for urban green space: a case study of Xuzhou central district," Scientia Geographica Sinica, vol. 39, no. 11, pp. 1771-1779, 2019, in Chinese.

[42] Z. Yuan, X. Wu, S. Zang, C. Wu, and M. Li, "Cooling effect of green patche based on TM image in Harbin downtown city," Scientia Geographica Sinica, vol. 37, no. 10, pp. 1600-1608, 2017, in Chinese.

[43] L. Anselin, "Spatial econometrics," in A Companion to Theoretical Econometrics, B. Baltagi, Ed., Basil Blackwell, Oxford, UK, 2001.

[44] E. Talen and L. Anselin, "Assessing spatial equity: an evaluation of measures of accessibility to public playgrounds," Environment and Planning A: Economy and Space, vol. 30, no. 4, pp. 595-613, 1998.

[45] A. Guo, J. Yang, W. Sun et al., "Impact of urban morphology and landscape characteristics on spatiotemporal heterogeneity of land surface temperature," Sustainable Cities and Society, vol. 63, pp. 1-12, Article ID 102211, 2020.

[46] A. Getis and J. K. Ord, "The analysis of spatial association by use of distance statistics," Geographical Analysis, vol. 24, no. 3, pp. 189-206, 1992.

[47] World Health Organization, Urban Planning, Environment and Health: From Evidence to Policy Action, World Health Organization, Geneva, Switzerland, 2010, http://www.euro. who.int/_data/assets/pdf_file/0004/114448/E93987.pdf? ua $=1$.

[48] M. R. Maryanti, H. Khadijah, A. Muhammad Uzair, and M. A. R. Megat Mohd Ghazali, "The urban green space provision using the standards approach: issues and challenges of its implementation in Malaysia," Sustainable Development and Planning, vol. 210, pp. 369-379, 2016.

[49] T. Morar, R. Radoslav, L. C. Spiridon, and L. Păcurar, "Assessing pedestrian accessibility to green space using GIS," Transylvanian Review of Administrative Sciences, vol. 10, no. 42, pp. 116-139, 2014.

[50] P. Fan, L. Xu, W. Yue, and J. Chen, “Accessibility of public urban green space in an urban periphery: the case of Shanghai," Landscape and Urban Planning, vol. 165, pp. 177-192, 2016.

[51] E. Richardson, J. Pearce, R. Mitchell, P. Day, and S. Kingham, "The association between green space and cause-specific mortality in urban New Zealand: an ecological analysis of green space utility," BMC Public Health, vol. 10, no. 240, pp. 1-14, 2010.
[52] H. Ernstson, "The social production of ecosystem services: a framework for studying environmental justice and ecological complexity in urbanized landscapes," Landscape and Urban Planning, vol. 109, no. 1, pp. 7-17, 2012.

[53] J. Byrne and J. Wolch, "Nature, race, and parks: past research and future directions for geographic research," Progress in Human Geography, vol. 33, no. 6, pp. 743-765, 2009.

[54] A. R. Maroko, J. A. Maantay, N. L. Sohler, K. L. Grady, and P.S. Arno, "The complexities of measuring access to parks and physical activity sites in New York city: a quantitative and qualitative approach," International Journal of Health Geographics, vol. 8, no. 1, p. 34, 2009.

[55] D. Wang, G. Brown, and Y. Liu, "The physical and nonphysical factors that influence perceived access to urban parks," Landscape and Urban Planning, vol. 133, pp. 53-66, 2015.

[56] C. Coutts, M. Horner, and T. Chapin, "Using geographical information system to model the effects of green space accessibility on mortality in Florida," Geocarto International, vol. 25, no. 6, pp. 471-484, 2010.

[57] S. Yang, A. Guariglia, and N. Horsewood, "To what extent is the Chinese housing boom driven by competition in the marriage," Journal of Housing and the Built Environment, 2020.

[58] D. J. Nowak, R. A. Rowntree, E. G. McPherson, S. M. Sisinni, E. R. Kerkmann, and J. C. Stevens, "Measuring and analyzing urban tree cover," Landscape and Urban Planning, vol. 36, no. 1, pp. 49-57, 1996.

[59] E. Talen, "The spatial logic of parks," Journal of Urban Design, vol. 15, no. 4, pp. 473-491, 2010.

[60] S. Chen, K. M. Christensen, and S. Li, "A comparison of park access with park need for children: a case study in cache county, Utah," Landscape and Urban Planning, vol. 187, pp. 119-128, 2019.

[61] J. L. Crompton and B. E. Wicks, "Implementing a preferred equity model for the delivery of leisure services in the US context," Leisure Studies, vol. 7, no. 3, pp. 287-304, 1988.

[62] W. Lucy, "Equity and planning for local services," Journal of the American Planning Association, vol. 47, no. 4, pp. 447-457, 1981.

[63] A. Loukaitou-Sideris and O. Stieglitz, "Children in Los Angeles parks: a study of equity, quality and children's satisfaction with neighbourhood parks," Town Planning Review, vol. 73, no. 4, pp. 467-488, 2002.

[64] E. Talen, "Neighborhoods as service providers: a methodology for evaluating pedestrian access," Environment and Planning B: Planning and Design, vol. 30, no. 2, pp. 181-200, 2003.

[65] J. Byrne and N. Sipe, Green and Open Space Planning for Urban Consolidation - A Review of the Literature and Best Practice, Urban Research Program, Brisbane, Australia, 2010.

[66] D. Guan, L. Lei, and Z. Han, "Spatial-temporal variation of population aging: a case study of China's Liaoning province," Complexity, vol. 2020, Article ID 5436061, 2020. 